\title{
BMC Energy: a home for all energy and fuels research
}

Harriet E. Manning ${ }^{1 *}$, Jo-Shu Chang ${ }^{2}$, Huazhen Fang ${ }^{3}$, Geoffrey Hammond ${ }^{4}$, Yongheng Yang ${ }^{5}$ and Sang Yup Lee ${ }^{6}$

\begin{abstract}
This editorial accompanies the full launch of the latest new BMC Series journal, BMC Energy. Written jointly by the journal Section Editors, the Chair of the Editorial Advisory Board and the Editor at Springer Nature, this editorial outlines how this new journal plans to serve the energy research community and describes in detail the scope of the work that it hopes to attract. BMC Energy joins a number of new physical science journals that have been launched recently in the BMC Series, each following BMC Series' ethos of openness and inclusivity, aiming to publish quality research that is accessible for all.
\end{abstract}

\section{Introduction}

The Fifth Assessment Report of the Intergovernmental Panel on Climate Change (2013; the most recent report) asserts that it is 'extremely likely' that the most dominant cause of the observed increase in global temperatures since the mid-twentieth century is anthropogenic release of greenhouse gases [1]. Carbon dioxide released during the burning of fossil fuels accounts largely for this, the concentration of atmospheric $\mathrm{CO}_{2}$ having risen about $40 \%$ since pre-industrial times.

The 2015 Paris Agreement on climate change aims to keep global temperatures "well below $2^{\circ} \mathrm{C}$ above pre-industrial levels and to pursue efforts to limit the temperature increase to $1.5^{\circ} \mathrm{C}$ above pre-industrial levels" however, the world still faces significant and imminent challenges in order to bring global warming into line with the aspirations of the Paris Agreement [2]. In today's rapidly developing energy market, fossil fuels continue to represent a vital energy source. In order to ensure future energy security and to counteract the damaging long-term effects of fossil fuel use on the climate and environment, there is an urgent global need to reduce our fossil fuel reliance. It is also expected that global energy demand will increase as we move into the era of the fourth industrial revolution, as information and communication technologies are seamlessly being integrated with all types of industries and our everyday lives.

\footnotetext{
* Correspondence: Harriet.Manning@springernature.com

${ }^{1}$ Springer Nature, 4 Crinan Street, London N1 9XW, UK

Full list of author information is available at the end of the article
}

At the same time, we can increase energy efficiency using such integrated technologies.

It is widely accepted that one source of renewable energy will not be able to replace fossil fuels in the foreseeable future [3] and that instead a combination of difference energy sources will be the answer for long-term energy security. This presents many challenges from an energy systems point of view, as these different sources must be integrated on a regional, national and even global scale to ensure a continuous, reliable energy supply. Further to this, in the shorter term the challenge is to slowly reduce our reliance on fossil fuels by integrating renewable sources of energy into existing systems and processes [4].

This new addition to the BMC Series portfolio of open, inclusive, community journals aims to disseminate the latest energy research as widely as possible, enabling researchers across the globe to advance towards meeting humanity's future energy challenges. BMC Energy will make all published articles immediately available for all to read and reuse by publishing under the CC-BY licence [5]. This Editorial describes in detail the scope of each of the Sections and outlines what BMC Energy aims to offer to the energy community.

\section{Aims and scope}

BMC Energy welcomes fundamental and applied research across the multidisciplinary energy and fuels research field. The journal is divided into four distinct sections that cover low carbon energy generation, bioenergy, energy 
storage, and energy systems, processes, planning and policy.

There is a great deal of ongoing work in improving energy materials, devices and infrastructure to provide low carbon energy generation more efficiently, at lower costs and without using rare or harmful materials. For example, perovskite solar cells were first developed over 10 years ago and the advancements in the technology over that time have been, and continue to be, remarkable [6]. However, challenges of device stability, environmental impact and efficiency remain for widespread solar energy generation and across many forms of renewable energy generation.

The challenge of developing energy storage mechanisms to enable a sustainable, continuous energy supply from renewable sources brings together researchers across many different disciplines. For example, compressed air energy storage is being investigated as a more universal energy storage solution than hydro storage, which is limited to areas with suitable geographical conditions. The pores between grains of rock in the earth could potentially store sufficient compressed air to provide seasonal energy storage [7]. In electrochemical energy storage, improvements to battery technology need to be made to keep up with developments in other fields, such as electric vehicles.

The field of bioenergy offers huge potential for providing green alternatives to fossil fuels. Many challenges exist also, and cutting edge research is being conducted in this area from a molecular level up to plant operation level. The conversion of waste products to energy is of particular interest from a sustainability point of view, and $B M C$ Energy launches with an open call for papers on Advanced Biofuels for $\mathrm{CO}_{2}$ Mitigation.

Innovations and research, development and demonstration (RD\&D) in the areas of energy systems, processes, and systems integration are critical to securing a low carbon future. Electricity generation has historically been based around the concept of large, centralised (thermal) power stations: based on fossil fuel combustors and, more recently, nuclear reactors. This centralised model has delivered economies of scale and reliability, but it exhibits significant drawbacks. A move towards a more decentralised or distributed energy system that utilises renewable energy technologies is consequently desirable. Contributions are therefore needed in terms of energy systems integration that brings together power generation, the processing and transmission of energy carriers, and energy end-use. 'Governance' issues, including energy and environmental regulation, are prime movers of energy market development and planning. They provide important tools for policymakers.

$B M C$ Energy publishes mainly research and review articles in each of the four journal sections. We are delighted to welcome Professor Jo-Shu Chang (National Cheng Kung University, Taiwan), Dr. Huazhen Fang (University of Kansas, USA), Professor Geoffrey Hammond (University of Bath, UK) and Dr. Yongheng Yang (Aalborg University, Denmark) as Section Editors for the Journal [8], as well as our international team of Editorial Board Members and Editorial Advisors [9]. The Sections [10] are introduced by the respective Section Editors here.

\section{Editorial sections \\ Low carbon energy generation}

The increasing concern for the global environment and the foreseen exhaustion of fossil fuel-based energy drive the development and exploitation of new energy generation technologies with substantially lower amounts of carbon dioxide emissions. It further accelerates the energy paradigm transition from far and wide and significant attempts have been made to tackle emerging issues. In this context, this section is dedicated to collecting the latest research on the development, design, optimization, control, and application of Low Carbon Energy (e.g., solar photovoltaics, wind energy, hydropower, wave and tidal energy). This includes, but is not limited to:
- Materials and sources of low carbon energy
- Renewable energies
o Hydropower systems
- Nuclear power generation
- Energy capture and harvesting
- New energy conversion technologies
o Energy utilization and application
o System design, optimization, and control
- Low carbon energy management
$\circ$ Energy efficiency and reliability

Novel energy harvesting devices with zero or low carbon emissions and cost-effective exploitation of low carbon energy will, in particular, be considered. Submissions should highlight the original contributions in either technological improvements or practical implementations. In addition, methodology articles and reviews are also welcome.

\section{Bioenergy (biofuels, biomass and biogas)}

Bioenergy is defined as renewable energy derived from biological matter or "biomass". With the advancement of technology, the bioenergy industry has been emerging diversely and also takes a significant responsibility in the world energy sector. The energy stored in the biomass is able to generate renewable electricity, thermal energy (biogas), or transportation fuels (biofuels). Agricultural and domestic waste biomass contributes to the production of biofuel and biogas including biomethane, bioethanol, biodiesel and biobutanol. Chemical and biochemical 
engineering plays a key role in the development of sustainable technology for bioenergy production. This includes advancement of process and systems to reduce the production cost and environmental impact.

The section publishes high quality, novel and functional developments in the area of bioenergy, biofuels and biogas development and processing. This section aims to solve bioenergy production challenges encountered in emerging technologies. BMC Energy welcomes submissions on biomass conversion and energy processes and systems, involving innovative engineering technology that could address the challenges encountered in bioenergy production. In general, the section welcomes papers on the following topics:

- Current and emerging biomass feedstocks and engineering processes that are involved in bioenergy production.

- Energy harnessing from a wide variety of biomass feedstocks; feedstock development, including first, second and third generation biofuels; residual biomass and municipal waste.

- Advanced processes and technologies enabling the development of alternative energy sources.

- Chemical, biochemical, and thermochemical conversion processes involving bioenergy production.

- Engineering design and technology operations in bioenergy conversion processes.

\section{Energy storage}

An engine of the world's economy, the energy industry is now transforming at an unprecedented breadth and depth in its generation, delivery and use toward higher efficiency, cleanliness, affordability and sustainability. Meanwhile, new energy consumption landscapes are forming due to the rapid growth of electrified transportation, renewable energy, energy-aware buildings and smart grid. These factors have driven an ever-increasing demand for energy storage in different forms, including electrochemical, chemical, thermal and mechanical. This has motivated a tremendous amount of research from both the academic and industrial communities, and the scope for future innovation is nothing less than limitless.

To further grow this area, this section aims to publish up-to-date research tackling challenges relevant to technological development, economy and policy making. This section welcomes original research articles and reviews on topics including but not limited to the following:

- Design, fabrication and manufacturing of different energy storage systems (batteries, fuel cells, flywheels, thermal and compressed air energy storage, etc.)

- New energy storage approaches and systems
- First-principles and data-driven modelling to characterize the dynamic behaviour in energy storage and release

- Energy storage model analysis, identification and validation

- Optimal operation and control of energy storage systems

- Optimal management of systems and applications involving energy storage

- Environmental impact and sustainability analysis of energy storage

- Economic analysis and market assessment of energy storage technologies

- Energy storage policy development, analysis and evaluation

\section{Energy systems, processes, planning and policy}

Achieving greenhouse gas emission reductions in line with the requirements of the 2015 Paris Agreement will require a challenging transition that will produce, deliver and use energy which is not only low carbon, but also secure and affordable; thus resolving the so-called energy policy 'trilemma'. This will necessitate innovations and research, development and demonstration (RD\&D) in the areas of energy systems, processes, and systems integration. Such systems would embrace power generation, the processing and transmission of energy carriers, energy storage systems, and energy end-use.

Core research topics in this Section include energy conversion, energy efficiency and demand reduction techniques, as well as industrial decarbonisation. Chemical processes give rise to 'process emissions', such as those associated with cement production, that need to be addressed in addition to those emissions derived from direct energy requirements. The preferred route to a decarbonised power generation system is likely to be some mix of renewables [e.g., bioenergy, onshore and offshore wind power, solar photovoltaic (PV) arrays and solar thermal systems], nuclear power and fossil-fuelled power plants with carbon capture and storage (CCS). However, the present cohort of energy system models exhibit weaknesses that undermine their capacity to inform and promote improved policy interventions and planning decisions.

Methods will consequently be required that include technology assessment, systems analysis, and the optimization of energy processes, along with the evaluation of energy policy instruments and strategies that may incorporate energy and environmental regulation. They may comprise empirical research, mathematical simulation (including energy-economic modelling), and case studies. Energy systems integration (ESI) is also needed to ensure that individual energy systems work efficiently with one another. These may be significantly different from current approaches, involving multi-vector holistic modelling. Thus, ESI brings 
together a variety of energy carriers (including fuels, electricity, and alternative thermal sources) potentially with energy system infrastructures, such as data, transportation, and water networks. It will therefore aid the provision of a more rigorous underpinning for future energy systems planning and policy formulation out to 2050 and beyond.

There are various types of energy policy intervention into the marketplace, including R\&D support by way of research programmes and grants to encourage academic, public, and private $R \& D$, or the provision of trained scientists. Market development policies might include feed-in tariffs, tax credits, and the creation of niche markets. New, low carbon technologies can then develop with a degree of protection from incumbent energy market actors. Finally, competition policies are appropriate for technologies approaching maturity, and aim to support their further commercialisation towards full competitiveness, whilst ensuring cost-effective energy for consumers.

\section{Conclusion}

$B M C$ Energy aims to provide the energy and fuels research community with an open, inclusive an authoritative venue to publish the latest research developments. By making all articles immediately accessible upon publication, it hopes to aid the dissemination of knowledge so that researchers can advance closer towards a solution to our global energy challenges.

We hope that you find the first group of articles interesting and valuable, and we look forward to working closely with our authors, editors, reviewers and readers to ensure BMC Energy is a valuable resource within the energy research community.

\section{Acknowledgements}

Not applicable.

Funding

Not applicable.

Availability of data and materials

Not applicable.

\section{Authors' contributions}

HM, GH and SL wrote the introduction, aims and scope and conclusion. JC, $H F, G H$ and $Y Y$ wrote the editorial sections. All authors read and approved the final version of the manuscript.

\section{Competing interests}

$\mathrm{HM}$ is the Editor of BMC Energy and an employee of Springer Nature. JC, HF, $\mathrm{GH}, \mathrm{YY}$ and $\mathrm{SL}$ are members of the Editorial Board of BMC Energy.

\section{Publisher's Note}

Springer Nature remains neutral with regard to jurisdictional claims in published maps and institutional affiliations.

\section{Author details}

${ }^{1}$ Springer Nature, 4 Crinan Street, London N1 9XW, UK. ²Department of Chemical Engineering, National Cheng Kung University, Tainan City, Taiwan.

${ }^{3}$ Department of Mechanical Engineering, University of Kansas, Lawrence,
USA. ${ }^{4}$ Department of Mechanical Engineering, University of Bath, Bath, UK. ${ }^{5}$ Department of Energy Technology, Aalborg University, Aalborg, Denmark. ${ }^{6}$ Department of Chemical \& Biomolecular Engineering, Korea Advanced Institute of Science and Technology, Daejeon, Republic of Korea.

Received: 19 March 2019 Accepted: 8 April 2019

Published online: 16 May 2019

\section{References}

1. IPCC. In: Stocker TF, Qin D, Plattner G-K, Tignor M, Allen SK, Boschung J, Nauels A, Xia Y, Bex V, Midgley PM, editors. Climate Change 2013: The Physical Science Basis. Contribution of Working Group I to the Fifth Assessment Report of the Intergovernmental Panel on Climate Change. Cambridge, United Kingdom and New York, NY, USA: Cambridge University Press; 2013. p. 1535.

2. United Nations/Framework Convention on Climate Change. Adoption of the Paris agreement, 21 st conference of the parties. Paris: United Nations; 2015.

3. International Energy Agency. World Energy Outlook 2011 179,186 http://www.worldenergyoutlook.org/ (International Energy Agency, 2011).

4. Centi, et al. Chemical engineering role in the use of renewable energy and alternative carbon sources in chemical production. BMC Chemical Engineering. 2019;1:5.

5. Creative Commons Attribution License, Creative Commons Attribution License. [Online]. Available: http://creativecommons.org/licenses/by/4.0/

6. A decade of perovskite solar cells. Nat Energy 2019;4:1 https://www.nature. com/articles/s41560-018-0323-9.

7. Mouli-Castillo, et al. Inter-seasonal compressed-air energy storage using saline aquifers. Nat Energy. 2019;4:131-9.

8. BMC Energy Editor Profiles [Online]. Available https://bmcenergy.biomedcentral. com/about/editorial-board/editor-profiles

9. BMC Energy Editorial Board [Online]. Available https://bmcenergy.biomedcentral. com/about/editorial-board

10. BMC Energy Sections and Section scopes [Online]. Available https://bmcenergy. biomedcentral.com/articles/sections1.

Ready to submit your research? Choose BMC and benefit from:
- fast, convenient online submission
- thorough peer review by experienced researchers in your field
- rapid publication on acceptance
- support for research data, including large and complex data types
- gold Open Access which fosters wider collaboration and increased citations
- maximum visibility for your research: over 100M website views per year
At BMC, research is always in progress.
Learn more biomedcentral.com/submissions

